\title{
Circadian Variation of Exhaled Nitric Oxide and Urinary Eosinophil Protein $X$ in Asthmatic and Healthy Children
}

\author{
JOERG MATTES, KARIN STORM VAN'S GRAVESANDE, CAROLINE MOELLER, \\ MICHAEL MOSELER, MATTHIAS BRANDIS, AND JOACHIM KUEHR \\ University Children's Hospital Freiburg, D-79106 Freiburg, Germany [C.M., M.M., M.B., J.K.]; Division \\ of Biochemistry and Molecular Biology, John Curtin School of Medical Research, Australian National \\ University, Canberra ACT 0200, Australia [J.M.]; and Brigham and Women's Hospital, Harvard Medical \\ School, Pulmonary Division, Boston, MA 02115, U.S.A. [K.S.v.G.]
}

\begin{abstract}
Asthmatic symptoms and the frequency of admissions to hospital because of acute asthma tend to increase in the early morning hours, and it is therefore possible that airway inflammation increases during the night. To elucidate the hypothetical circadian variation of airway inflammation, we measured concentrations of exhaled nitric oxide (FeNo), urinary eosinophil protein $\mathrm{X}$ excretion (EPX), and forced expiratory volume in the first second $\left(\mathrm{FEV}_{1}\right)$ in 20 asthmatic and 6 nonatopic nonasthmatic children every $3 \mathrm{~h}$ during a $21 \mathrm{~h}$ period. Compared with control subjects, asthmatic subjects had higher FeNo (median, 22.7 versus $10.3 \mathrm{ppb}, p=0.016$ ) and lower $\mathrm{FEV}_{1} \%$ predicted (median, 91.0 versus $101.9 \%, p=0.045$ ), but did not differ significantly in EPX (median, 153.8 versus $148.7 \mu \mathrm{g} / \mathrm{mmol}$ creatinine, $p=0.83$ ) at 7 AM. However, differences in gender and age do not allow direct comparisons between asthmatic and control children. FeNo and EPX demonstrated a cosinelike circadian rhythm $(\log \mathrm{FeNo}, p=0.0001 ; \log \mathrm{EPX}, p=0.0001)$ with lowest levels at $7 \mathrm{PM}$ and highest at $7 \mathrm{AM}$. This was also the case for $\mathrm{FEV}_{1} \%(p=0.01)$. No difference in the amplitude
\end{abstract}

\section{ABSTRACT}

of circadian rhythm was observed between asthmatic and healthy control children for log FeNo $(p=0.35), \log \operatorname{EPX}(p=0.57)$, and $\mathrm{FEV}_{1} \%(p=0.17)$. A stratified analysis showed a significant circadian rhythm in the control group for $\log$ FeNo $(p=$ $0.014)$ and $\log \operatorname{EPX}(p=0.0001)$. Our results therefore suggest a circadian rhythm of inflammatory markers, which peaks in the early morning. Rhythmicity of EPX excretion and FeNo in healthy children suggests a physiologic mechanism; however, pathologic effects during the night might occur under conditions of asthma-specific inflammation. (Pediatr Res 51: 190-194, 2002)
FeNo, exhaled nitric oxide
Abbreviations
EPX, eosinophil protein X
$\mathbf{F E V}$, forced expiratory volume in the first second
NO, nitric oxide
GR, glucocorticoid receptor

Asthmatic symptoms and the frequency of admissions to hospital because of acute asthma tend to increase in the early morning hours, but the underlying mechanisms of this observation are not fully understood. One explanation is that airway inflammation increases during the night as a higher number of eosinophils and $\mathrm{CD}^{+}{ }^{+}$lymphocytes have been observed in bronchial biopsies of asthmatics taken at night compared with those obtained during the afternoon (1-3). The possibility of investigating a proposed circadian variation of airway inflammation at multiple time points by bronchial biopsies is limited by their invasive character. However, noninvasive procedures

Received November 9, 2000; accepted June 11, 2001

Correspondence and reprint requests: Joachim Kuehr, M.D., University Children's Hospital Freiburg, Mathildenstr.1, D-79106 Freiburg, Germany; e-mail: kuehr@kikli.ukl.uni-freiburg.de

J.M. is supported by the German Research Association (grant no. MA 2241/1-1). are suitable for elucidating a circadian rhythm as well as the peak of airway inflammation in childhood asthma. In this regard the measurement of eosinophilic markers such as eosinophil cationic protein and EPX in blood and urine samples as well as the measurement of the concentration of FeNo have been suggested as noninvasive ways of investigating airway inflammation (4-7). EPX is released by activated eosinophils into the tissue and circulation, and can be detected in urine (8), whereas NO is released by an inducible calcium-independent NO synthase during airway inflammation and can be detected in exhaled air (9). It has been observed that levels of urinary EPX and exhaled NO are higher in asthmatic individuals than healthy control subjects $(7,10,11)$. In addition, close correlations have been seen between levels of eosinophil cationic protein in sputum and both urinary EPX and FeNo (12). A recent study has shown higher levels of urinary EPX in the 
morning in asthmatic children (13). Interestingly this was also observed in a nonatopic nonasthmatic control group, suggesting primarily a physiologic basis for this observation (14).

To further elucidate a proposed circadian variation of inflammatory activity, we measured FeNo, urinary EPX excretion, and lung function in stable asthmatic children and nonasthmatic control subjects during a 21-h study period. As cortisol is suggested as counteracting inflammatory activity, we also investigated endogenous cortisol release in saliva in parallel.

\section{METHODS}

Population. Twenty children with stable asthma according to international recommendations (15) who had been taking inhaled corticosteroids (100-400 $\mu \mathrm{g}$ budesonide bid; $n=13$ ), sodium cromoglycate ( $20 \mathrm{mg}$ three times per day, $n=2$ ), or $\beta_{2}$-adrenergic agonists as needed (salbutamol or terbutaline $n=5$ ) for at least 6 mo were recruited from the outpatient department of the University Children's Hospital Freiburg. Additionally, six children without atopic disorders (asthma, hay fever, and eczema), with no sensitization to common inhalant allergens and with no history of parental asthma, were included.

Study design. Written informed consent was obtained, peak expiratory flow was measured, and respiratory symptoms were recorded in the patient's home at $7 \mathrm{AM}$ and $7 \mathrm{PM}$ on five consecutive days. The children were then admitted to the hospital for a 21-h study period. Lung function, FeNo, urinary EPX excretion, and salivary cortisol were measured at $10 \mathrm{AM}$, $1 \mathrm{PM}, 5 \mathrm{PM}, 7 \mathrm{PM}$, and $10 \mathrm{PM}$ on the first day, and at $1 \mathrm{AM}$, $4 \mathrm{AM}$, and $7 \mathrm{AM}$ of the next day. To achieve maximal uniformity, measurements of lung function, FeNo, and urinary analysis were all conducted each by the same person in both surveys. To maintain constant conditions, antiinflammatory therapy (inhaled corticosteroids, sodium cromoglycate) was continued during the surveys (11 AM and $11 \mathrm{PM}$ ), but $\beta_{2}$ adrenergic agonists were withheld $12 \mathrm{~h}$ before admission and during observation. None of the children required rescue treatment during the study period. The study was approved by the ethics committee of the University Hospital Freiburg.

Peak flow measurement and daily diary. With the use of a mini Wright Peak Flow Meter (Clement Clarke, Ltd., London, United Kingdom), the highest of three peak expiratory flow rate readings was recorded twice a day for $5 \mathrm{~d}$ in a daily diary. Additionally, respiratory complaints (wheezing, dyspnea and shortness of breath, cough) were recorded twice a day in the diary.

Measurement of exhaled NO. FeNo was measured during a single-breath exhalation by means of a computerized system for online recordings (Exhaled Breath Analyser; Aerocrine $\mathrm{AB}$, Stockholm, Sweden) with a chemiluminescence analyser (CLD 77AM; Eco Physics, Duernten, Switzerland) as described previously (12) according to European Respiratory Society recommendations (16). The analyzer had a response time of $100 \mathrm{~ms}$ and a detection limit of 0.1 parts per billion (ppb). In brief, two-point calibrations ( $80 \mathrm{ppm}$ NO balanced with $\mathrm{N}_{2}$ ) and $\mathrm{NO}$ zeroing (NO-free air) were set before the measurements. Children inhaled NO-free air to avoid contamination with ambient NO (17), and performed a slow vital capacity maneuver with a target flow of $70 \mathrm{~mL} / \mathrm{s}$. The flow was measured by a heated pneumotachograph (Hans Rudolph, Kansas City, KS, U.S.A.) and displayed online to provide visual guidance and maintain the exhalation flow. A fixed expiratory resistance with approximately $100 \mathrm{~cm} \mathrm{H}_{2} \mathrm{O} / \mathrm{L} / \mathrm{s}$ (Hans Rudolph) was used to increase oral pressure. This was shown to prevent contamination with NO from the nasopharynx (18). Exhaled air was led via a nonrebreathing valve (Hans Rudolph) into a Teflon tubing system connected to the analyzer and continuously sampled from the exhalation limb of the system. After a 15- to 20-s period of exhalation, mean FeNo values were calculated from the 60 to $90 \%$ part of the exhalation, which forms the plateau level of the NO concentration (12).

Spirometry. After the FeNo measurement children underwent spirometry according to international guidelines (19). Briefly the highest $\mathrm{FEV}_{1}$ of two reproducible flow-volume curves (difference between forced vital capacities $\leq 5 \%$ ) was recorded by using a Masterscope 4.0 (Fa. E. Jaeger, Würzburg, Germany). $\mathrm{FEV}_{1}$ was presented as a percentage of predicted value for each child's height and weight (20).

Analysis of salivary cortisol. Unstimulated saliva samples were collected and immediately frozen at $-70^{\circ} \mathrm{C}$ until further analysis. Cortisol concentration was determined by RIA, which does not detect budesonide (AMERLITE Cortisol Assay; Johnson \& Johnson Clinical Diagnostics, Neckargemünd, Germany).

Analysis of urinary EPX and creatinine. Portions of urine were collected and immediately frozen at $-70^{\circ} \mathrm{C}(12)$. Levels of urinary EPX were measured with a double antibody RIA (Pharmacia \& Upjohn, Freiburg, Germany). Measurement of urine creatinine was performed by using the alkaline picrate method (Jaffé reaction) (21). Results of urinary EPX excretion were presented in micrograms per millimole creatinine.

Statistical analysis. FeNo, urinary EPX excretion, and FEV 1 $\%$ of predicted value were described as median and 25 th-75th percentiles. Values of asthmatic and nonatopic children were compared using the Wilcoxon two-sample test. The relation between the variables was calculated using Spearman's rank correlation coefficients. In accordance with an earlier report (22), the natural logarithms of the eight measurements of each variable (exception: $\mathrm{FEV}_{1} \%$ ) were analyzed longitudinally through repeated measurement regression analysis (PROC MIXED). The circadian rhythm was modeled by using a sine and a cosine function of time (with a 1-d period) as explanatory variables through COSINOR analysis (23) and including sex as a confounding variable. To test for different circadian rhythms for asthmatic and control children, the interaction between the sine/cosine terms and the group variable [sine/cosine * group] were added to the model. A $p$ value of $<0.05$ was considered significant. Data were analyzed using the Statistical Analysis System 6.12 (SAS Institute, Cary, NC, U.S.A.).

\section{RESULTS}

Population characteristics. The asthmatic population and the nonasthmatic nonatopic control population are character- 
ized in Table 1. In all analyzed subjects $(n=26)$, the mean of the eight individual FeNo measurements was significantly correlated to mean urinary EPX excretion $\left(r_{\mathrm{s}}=0.42 ; p=\right.$ 0.04), whereas neither mean FeNo nor mean EPX were correlated with mean $\mathrm{FEV}_{1} \%\left(r_{\mathrm{s}}=-0.02\right.$ and $r_{\mathrm{s}}=-0.04$ respectively; $p>0.5$ ).

Bivariate analysis of circadian variation of FeNo, urinary EPX, lung function, and cortisol. Compared with control subjects, asthmatics had a higher FeNo (median, 22.7 versus $10.3 \mathrm{ppb} ; p=0.016$ ) and a lower $\mathrm{FEV}_{1} \%$ (median, 91.0 versus $101.9 \% ; p=0.045$ ), but no statistically significantly different EPX excretion (median, 153.8 versus $148.7 \mu \mathrm{g} / \mathrm{mmol}$ creatinine; $p=0.83$ ) at $7 \mathrm{AM}$. Analyzing the circadian change in the whole population $(n=26)$, only EPX excretion showed significantly higher values at $7 \mathrm{AM}$ than at $7 \mathrm{PM}$ (median, 148.7 versus $34.8 \mu \mathrm{g} / \mathrm{mmol}$ creatinine; $p=0.0001$ ), whereas for FeNo only a statistical trend toward higher morning values (median, 20.7 versus $11.0 \mathrm{ppb} ; p=0.07$ ) was seen. For $\mathrm{FEV}_{1}$ $\%$ no difference (median, 94.3 versus $96.0 \% ; p=0.59$ ) was observed (Figs. 1-3). Salivary cortisol levels were significantly higher at $0700 \mathrm{~h}$ than at $7 \mathrm{PM}$ (median, 36 versus $9 \mu \mathrm{g} / \mathrm{dL}$; $p=0.0001$; Fig. 4).

COSINOR analysis of sine/cosine-like circadian rhythm of FeNo, urinary EPX, lung function, and cortisol in saliva. Using COSINOR analysis, the whole population $(n=26)$ showed significant sine/cosine-like rhythms for the logarithms of FeNo $(p=0.0001$; amplitude, 0.0986) and urinary EPX excretion ( $p=0.0001$; amplitude, 0.299). A weaker, but significantly circadian, variation was also observed for $\mathrm{FEV}_{1}$ $\%$ when all eight measurements were considered in the COSINOR analysis $(p=0.01$; amplitude, 1.77). As salivary cortisol levels could not be transformed to a normally distributed variable, it was not possible to perform a COSINOR analysis for this variable. On the basis of an interaction term, no differences between asthmatics and nonatopic nonasthmatic control subjects regarding the sine/cosine-like rhythm for log FeNo $(p=0.35), \log \operatorname{EPX}(p=0.57)$, and $\mathrm{FEV}_{1} \%(p=0.17)$ were observed. A separate analysis of the six nonasthmatic control subjects revealed a significant circadian rhythm only for $\log \operatorname{EPX}(p=0.0001)$ and $\log$ FeNo $(p=0.014)$, but not for $\mathrm{FEV}_{1} \%(p=0.5)$. Stratifying the analysis, budesonide-

Table 1. Characteristics of the study population\#

\begin{tabular}{|c|c|c|}
\hline Variable & $\begin{array}{c}\text { Nonasthmatic, } \\
\text { nonatopic control } \\
\text { subjects }(n=6)\end{array}$ & $\begin{array}{l}\text { Asthmatics } \\
(n=20)\end{array}$ \\
\hline Number (male/female) & $6(0 / 6)$ & $20(12 / 8)^{*}$ \\
\hline Age (y) & $12(9-13)$ & $13(9-14)$ \\
\hline $\begin{array}{l}\text { 7-19 h PEF variability at } \\
\text { home (\%) }\end{array}$ & $7.1(4.9-12.4)$ & $5.6(4.4-8.8)$ \\
\hline 7-19 h FEV 1 variability (\%) & $5.2(1.3-8.8)$ & $4.9(2.4-9.5)$ \\
\hline $\mathrm{FEV}_{1}(\%$ predicted $)$ & $104.5(97.8-117.6)$ & $91.7(77.6-102.0)^{*}$ \\
\hline $\mathrm{NO}(\mathrm{ppb})$ & $9.0(6.2-12.3)$ & $18.9(9.7-43.4)^{*}$ \\
\hline $\begin{array}{l}\text { Urinary EPX }(\mu \mathrm{g} / \mathrm{mmol} \\
\text { creatinine })\end{array}$ & $48.9(29.0-91.9)$ & $74.0(40.2-136.1)$ \\
\hline Cortisol $(\mu \mathrm{g} / \mathrm{dL})$ & $9(9-18)$ & $9(9-19)$ \\
\hline
\end{tabular}

$* p<0.05$ for asthmatics versus control subjects.

\# Median (25th-75th percentiles) of all individual measurements.

Abbreviation: PEF, peak expiratory flow. $\log \operatorname{EPX}[\mu \mathrm{g} / \mathrm{mmol}]$

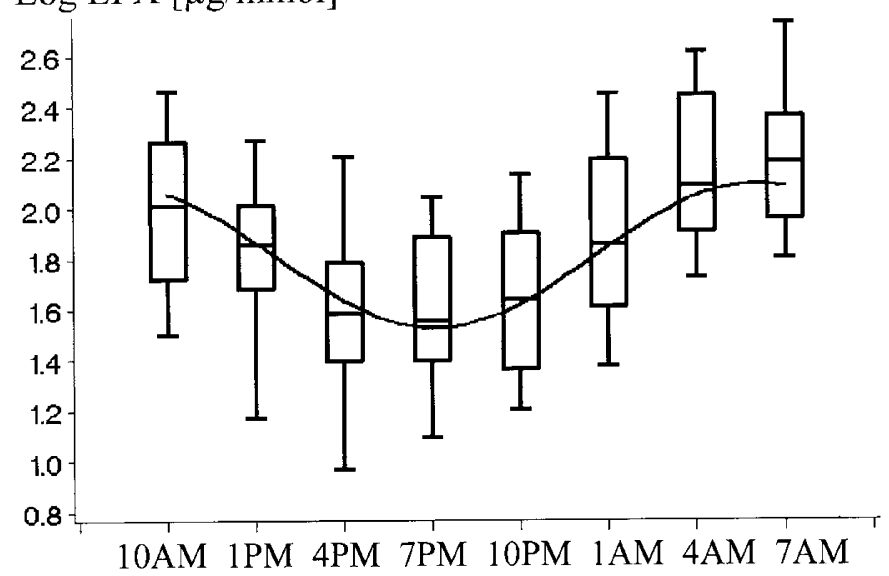

Figure 1. Logarithm of urinary EPX excretion in asthmatic and nonatopic nonasthmatic children during the 21-h study period. Lines within the box represent the medians, boxes represent the 25 th and 75 th percentiles, and bars represent the 10th and 90th percentiles. Curve represents the predicted circadian rhythm based on the COSINOR model.

\section{Log FeNO [ppb]}

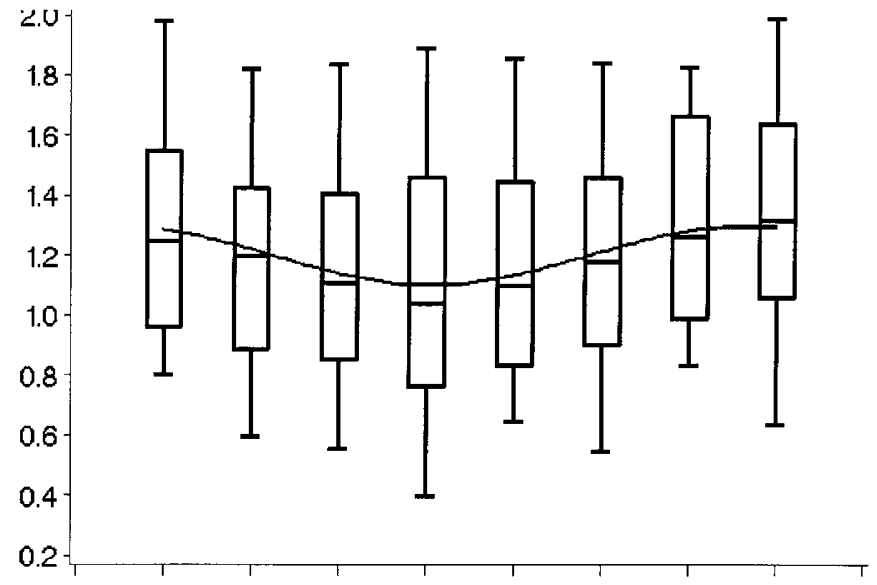

10AM 1PM 4PM 7PM 10PM 1AM 4AM 7AM

Figure 2. Logarithm of FeNo in asthmatic and nonatopic nonasthmatic children during the 21-h study period. Lines within the box represent the medians, boxes represent the 25 th and 75 th percentiles, and bars represent the 10th and 90th percentiles. Curve represents the predicted circadian rhythm based on the COSINOR model.

treated asthmatics $(n=13)$ as well as patients without inhaled steroids $(n=7)$ showed a circadian rhythm for $\log$ FeNo $(p=$ 0.0001 for both groups) and $\log$ EPX ( $p=0.0001$ for both groups), whereas $\mathrm{FEV}_{1} \%$ gained significance only in the group of asthmatics without budesonide $(p=0.008)$.

\section{DISCUSSION}

In this study we were able to demonstrate a cosinelike circadian rhythm for FeNo, urinary EPX, and $\mathrm{FEV}_{1} \%$ in a population comprising stable asthmatic children and nonasthmatic nonatopic control subjects. However, both study groups differ concerning sex and age, making it impossible to draw conclusions from comparisons of asthmatic and control children. Close correlations have been observed between FeNo, 


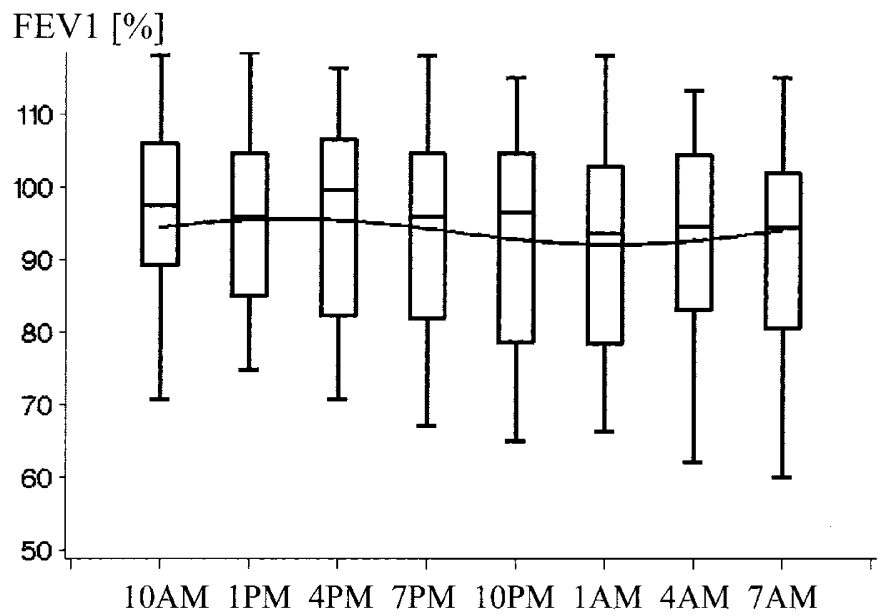

Figure 3. $\mathrm{FEV}_{1} \%$ in asthmatic and nonatopic nonasthmatic children during the 21-h study period. Lines within the box represent the medians, boxes represent the 25th and 75th percentiles, and bars represent the 10th and 90th percentiles. Curve represents the predicted circadian rhythm based on the COSINOR model.

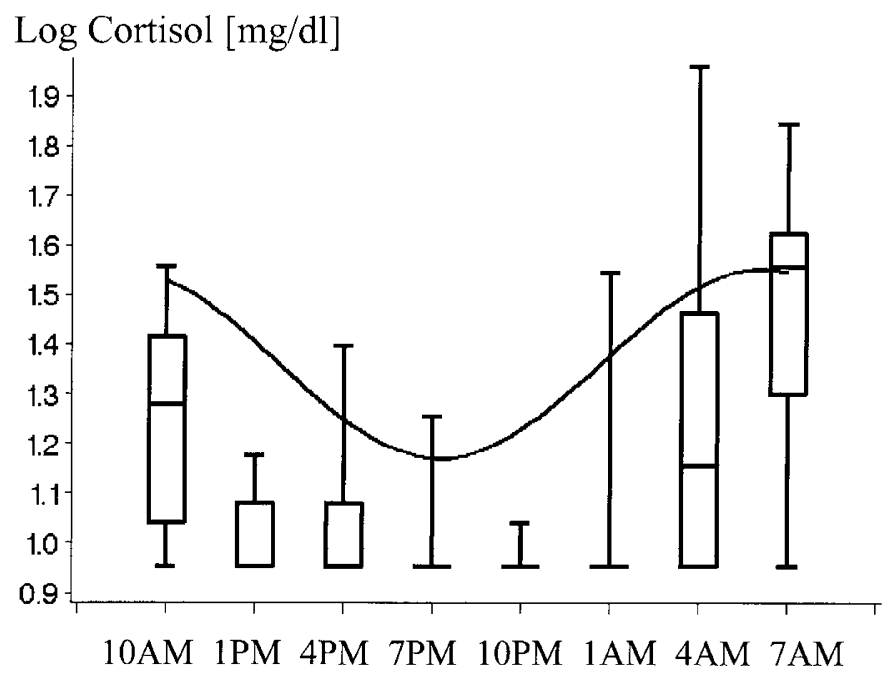

Figure 4. Logarithm of salivary cortisol in asthmatic and nonatopic nonasthmatic children during the 21 -h study period. Lines within the box represent the medians, boxes represent the 25th and 75 th percentiles, and bars represent the 10th and 90th percentiles. Curve represents the predicted circadian rhythm based on the COSINOR model.

urinary EPX excretion, and eosinophilic airway inflammation in asthmatics $(12,24)$. Hence the circadian variation of FeNo and urinary EPX found in this study may indicate a substantial nocturnal increase in activation of eosinophils as previously investigated in blood samples by Wempe et al. (25). In contrast to patients with nocturnal asthma, our population consisted of patients with stable asthma, who had neither a 5-d mean peak flow variability $>15 \%$ before admission nor reported nocturnal complaints in the diary. Thus it is unlikely that our findings are based on the clinical type nocturnal asthma, and we cannot elucidate whether patients with nocturnal asthma have a pronounced circadian variation. It could be argued that our findings are not related to nocturnal asthma as Ten Hackeren et al. (22) failed to demonstrate circadian variation of exhaled NO in six adult patients with nighttime complaints. However, in children different regulatory mechanisms of inflammation and a higher extent of circadian variation may be present. Thus we cannot exclude the relevance of our results for worsening of childhood asthma during the night.

A bias owing to $\beta_{2}$-agonist medication should be prevented, and in this study bronchodilators were withheld for $12 \mathrm{~h}$ before admission and during the survey. However, steroid treatment was continued during the study period (13 of 20 patients) to avoid unstable clinical conditions because of a washout period of steroids for a number of weeks. Obviously, the circadian rhythmicity of EPX and FeNo has not diminished in patients treated with inhaled corticosteroids, whereas a circadian rhythm of $\mathrm{FEV}_{1}$ could not be shown in patients treated with steroids $(p=0.5)$. In contrast, the subgroup with no steroids showed rhythmicity also for $\operatorname{FEV}_{1}(p=0.008)$. We speculate that $\mathrm{FEV}_{1}$, which is a relatively insensitive parameter, had been stabilized in steroid-treated patients. To explain our main finding three mechanisms must be considered: first, assuming the immunosuppressive effects of endogenous cortisol, we also investigated salivary cortisol levels during the study period. On average the lowest cortisol values were observed in the evening at the nadir of inflammatory markers. Given the delay between release and action of cortisol, it is possible that the physiologic dip in cortisol secretion during the evening could have resulted in a delayed increase of airway inflammation in the early morning $(26,27)$. Second, it can be seen that the inflammatory markers NO and EPX at 10 AM show lower values than at 7 AM. As the latter coincides with the physiologic cortisol peak, a subsequent antiinflammatory effect can be assumed. Third (and alternatively), responsiveness to endogenous cortisol owing to variation in the affinity of the GR may exhibit instantaneously a circadian variation and contribute to a nocturnal increase in inflammatory activity (28). In accordance with this concept, Kraft et al. (28) were able to demonstrate a reduced GR binding affinity and a reduced steroid responsiveness at 4 AM compared with 4 PM in asthmatics with complaints in the night. Regardless of which of the inhibitory effects on proinflammatory activity is more important, our finding of increasing EPX excretion and FeNo values during the night might be finally explained by a lack of inhibition of the glucocorticoid-sensitive transcriptional factor nuclear factor kappa-B, which also influences NO production (29).

The effect of cortisol is transduced by the GR, which can therefore also play a crucial regulatory role in inflammatory processes. In adults, circadian variation in exhaled NO was found neither in six patients with nocturnal asthma nor in eight patients without nocturnal asthma (22). This contrast to our findings in children raises the question of whether the number of GRs (30) and the circadian amplitude of cortisol release decrease with age $(31,32)$. The latter could be responsible for the circadian variation of exhaled NO observed in children yet not adults. In accordance with our results, Storm van's Gravesande et al. (13) demonstrated higher levels of urinary EPX excretion in the early morning compared with the afternoon in both healthy and asthmatic children. In the current investigation the rhythmicity of EPX excretion was not explained by the variation of creatinine clearance because EPX not corrected for creatinine also demonstrated an identical clear circadian vari- 
ation ( $p=0.0001$, data not shown). Even in our small control group, rhythmicity of log EPX and log FeNo gained statistical significance. Therefore, our current findings together with the earlier reports strongly suggest that circadian variation of inflammatory markers reflects primarily a physiologic regulation independent of both an endogenous factor such as asthma and environmental factors such as allergen exposure. The common physiologic mechanism regulating circadian rhythm of ACTH secretion and immunologic function is unknown, but is likely to be coupled to either sleep or an endogenous pacemaker.

Importantly, a rise in inflammatory markers during the night under acute asthma-specific conditions with a preexisting inflammatory process could result in pronounced pathologic effects at night. Our data show that subclinical effects on lung function related to peaks in inflammatory activity at night as a consequence of physiologic regulation are common even in stable asthma. Therefore we think that our findings could have potential therapeutic consequences not only in patients with nocturnal asthma but also in monitoring individual therapy when valid measurements of the inflammatory status within the airways are achieved. Particularly, in childhood asthma we try to find the lowest possible maintenance dose of corticosteroids to minimize the risk of a long-term burden of therapy owing to possible side-effects. Hence a circadian variation of the inflammatory process underlying asthma would suggest specifically targeting the morning peak of inflammatory activity by antiinflammatory therapy (33). In this respect, interventional studies appear to be both necessary and attractive.

Acknowledgment. The authors thank the 26 children for participating in the study and Christian Langrock for performing pulmonary function testing.

\section{REFERENCES}

1. Kraft M, Martin RJ, Wilson S, Djukanovic R, Holgate ST 1999 Lymphocyte and eosinophil influx into alveolar tissue in nocturnal asthma. Am J Respir Crit Care Med 159:228-234

2. Martin RJ 1998 Small airway and alveolar tissue changes in nocturnal asthma. Am J Respir Crit Care Med 157(suppl):S188-S190

3. Kraft M, Djukanovic R, Wilson S, Holgate ST, Martin RJ 1996 Alveolar tissue inflammation in asthma. Am J Respir Crit Care Med 154:1505-1510

4. Kharitonov SA, Barnes PJ 1996 Nitric oxide in exhaled air is a new marker of airway inflammation. Monaldi Arch Chest Dis 51:533-537

5. Koller DY, Halmerbauer G, Frischer T, Roithner B 1999 Assessment of eosinophil granule proteins in various body fluids: is there a relation to clinical variables in childhood asthma? Clin Exp Allergy 29:786-793

6. Shields MD, Brown V, Stevenson EC, Fitch PS, Schock BC, Turner G, Taylor R, Ennis M 1999 Serum eosinophilic cationic protein and blood eosinophil counts for the prediction of the presence of airways inflammation in children with wheezing. Clin Exp Allergy 29:1382-1389

7. Kristjansson S, Strannegard IL, Strannegard O, Peterson C, Enander I, Wennergren G 1996 Urinary eosinophil protein X in children with atopic asthma: a useful marker of antiinflammatory treatment. J Allergy Clin Immunol 97:1179-1187
8. Reimert CM, Minuva U, Kharazmi A, Bendtzen K 1991 Eosinophil protein X/eosinophil derived protein (EPX/EDN). Detection by enzyme-linked immunosorbent assay and purification from normal human urine. J Immunol Methods 141:97-104

9. Alving K, Weitzberg E, Lundberg JM 1993 Increased amount of nitric oxide in exhaled air of asthmatics. Eur Respir J 6:1368-1370

10. Hoekstra MO, Hovenga H, Gerritsen J, Kauffman HF 1996 Eosinophils and eosinophil-derived proteins in children with moderate asthma. Eur Respir J 9:2231-2235

11. Kharitonov SA, Yates DH, Robbins RA, Logan-Sinclair R, Shinebourne EA, Barnes PJ 1994 Increased nitric oxide in exhaled air of asthmatic patients. Lancet 343:133135

12. Mattes J, Storm van's Gravesande K, Reining U, Alving K, Ihorst G, Henschen M, Kuehr J 1999 NO in exhaled air is correlated with markers of eosinophilic airway inflammation in corticosteroid-dependent childhood asthma. Eur Respir J 13:13911395

13. Storm van's Gravesande K, Mattes J, Grüntjens T, Kopp M, Seydewitz HH, Moseler M, Kuehr J 1999 Circadian variation of urinary eosinophil protein X in asthmatic and healthy children. Clin Exp Allergy 29:1497-1501

14. O'Sullivan S, Kumlin M 1999 Eosinophil markers in childhood asthma. Clin Exp Allergy 29:1454-1456

15. National Asthma Education and Prevention Program Expert Panel Report 2: Guidelines from the Diagnosis and Management of Asthma. Rockville, MD: US Dept of Health and Human Services; 1997. NIH Publication 97-4051A

16. Kharitonov SA, Alving K, Barnes PJ 1997 Exhaled and nasal nitric oxide measurements: recommendations (ERS Task Force Report). Eur Respir J 10:1683-1693

17. Therminarias A, Flore P, Favre-Juvin A, Oddou M-F, Delaire M, Grimbert F 1998 Air contamination with nitric oxide: effect on exhaled nitric oxide response. Am J Respir Crit Care Med 157:791-795

18. Silkoff PE, McClean PA, Slutzky AS, Furlott HG, Hoffstein E, Wakita S, Chapman KR, Szalai JP, Zamel N 1997 Marked flow-dependence of exhaled nitric oxide using a new technique to exclude nasal nitric oxide. Am J Respir Crit Care Med 155:260267

19. American Thoracic Society 1987 Standardization of spirometry. Am Rev Respir Dis 136:1285-1298

20. Zapletal A 1987 Lung function in children and adolescents. In: Herzog, H (ed) Progress in respiration research. Karger, Basel, pp 173-196

21. Apple F, Brandt C, Prosch A, Erlandson G, Holmstrom V, Scholen J, Googins M 1986 Creatinine clearance: enzymatic versus Jaffé determination of creatinine in plasma and urine. Clin Chem 32:388-390

22. Ten Hacken NH, van der Vaart H, van der Mark TW, Koeter GH, Postma DS 1998 Exhaled nitric oxide is higher both at day and night in subjects with nocturnal asthma. Am J Respir Crit Care Med 158:902-907

23. Nelson W, Tong YL, Lee JK, Halberg F 1979 Methods for cosinor-rhythmometry. Chronobiologia 6:305-323

24. Piacentini GL, Bodini A, Costella S, Vicentini L, Mazzi P, Sperandio S, Boner AL 1999 Exhaled nitric oxide and sputum eosinophil markers of inflammation in asthmatic children. Eur Respir J 13:1386-1390

25. Wempe JB, Tammeling EP, Koeter GH, Hakansson L, Venge P, Postma DS 1992 Blood eosinophil numbers and activity during 24 hours: effects of treatment with budesonide and bambuterol. J Allergy Clin Immunol 90:757-765

26. Postma DS, Oosterhoff Y, AAlderen WMC, Kauffmann HF, Wempe JB, Koeter CH 1994 Inflammation in nocturnal asthma. Am J Respir Crit Care Med 150:83-86

27. Barnes PJ, Fitzgerald GA, Brown MJ, Dollery C 1980 Nocturnal asthma and changes in circulating epinephrine, histamine, and cortisol. N Engl J Med 303:263-267

28. Kraft M, Vianna E, Martin RJ, Leung DYM 1999 Nocturnal asthma is associated with reduced glucocorticoid receptor binding affinity and decreased steroid responsiveness at night. J Allergy Clin Immunol 103:66-71

29. Knowles RG, Salter M, Brooks SL, Moncada S 1990 Anti-inflammatory glucocorticosteroids inhibit the induction by endotoxin of nitric oxide synthase in the lung, liver and aorta of the rat. Biochem Biophys Res Commun 172:1042-1048

30. Tanaka H, Akama H, Ichikawa Y, Homma M, Oshima H 1991 Glucocorticoid receptors in normal leukocytes: effects of age, gender, season, and plasma cortisol concentrations. Clin Chem 37:1715-1719

31. Kiess W, Meidert A, Dressendorfer RA, Schriever K, Kessler U, Konig A, Schwarz HP, Strasburger CJ 1995 Salivary cortisol levels throughout childhood and adolescence: relation with age, pubertal stage, and weight. Pediatr Res 37:502-506

32. Van Cauter E, Leproult R, Kupfer DJ 1996 Effects of gender and age on the levels and circadian rhythmicity of plasma cortisol. J Clin Endocrinol Metab 81:2468-2473

33. Pincus DJ, Humeston TR, Martin RJ 1997 Further studies on the chronotherapy of asthma with inhaled steroids: the effect of dosage timing on drug efficacy. J Allergy Clin Immunol 100:771-774 